\title{
Arte, violencia y política en el arte latinoamericano
}

\section{Sebastián Vidal*}

http://dx.doi.org/10.22409/poiesis.1829.125143

\begin{abstract}
RESUMEN: Dentro de las representaciones de los lugares de la tortura en las dictaduras latinoamericanas, una de las propuestas visuales más interesantes se desarrolló en la ciudad de Rosario en el año 1968. En ese año, el Grupo de Arte de Vanguardia de Rosario desarrolló diversas acciones mancomunadas para denunciar la represión que vivía el país. Por aquellos años, la dictadura del general golpista Carlos Onganía pretendió alejar el fantasma del peronismo a través de una serie de medidas que apuntaron a debilitar el poder de sindicatos, congelar los sueldos, reprimir a los estudiantes y censurar espacios culturales. Al ver el estrangulamiento social, los artistas del Grupo de Artistas de Vanguardia, con financiamiento del Instituto Di Tella, propusieron un Ciclo de arte experimental que ofreció algunas de las obras más radicales del arte argentino en los años 60.
\end{abstract}

PALAVRAS-CLAVE: Grupo de Arte de Vanguardia de Rosario, arte experimental, años 60

ABSTRACT: Within the representations of places of torture in Latin American dictatorships, one of the most interesting visual proposals was developed in the city of Rosario in 1968. In that year, the Vanguard Art Group of Rosario developed several joint actions to denounce the repression that the country was living. In those years, the dictatorship of the coup General Carlos Onganía sought to remove the phantom of Peronism through a series of measures aimed at weakening the power of unions, freezing salaries, repressing students and censoring cultural spaces. Seeing the social strangulation, the artists of the Vanguardia Artists Group, with funding from the Di Tella Institute, proposed an experimental art cycle that offered some of the most radical works of Argentine art in the 60s.

KEYWORDS: Vanguard Art Group of Rosario, experimental art, 60s

\footnotetext{
*Sebastián Vidal Valenzuela es Ph.D. en Art History en la University of Texas, Austin, becado Fulbright. Magíster y Licenciatura en Historia y Teoría del arte en la Universidad de Chile, y en Educación Artística en la Pontificia Universidad Católica de Chile. Trabaja como Director del programa de Historia y Teoría del arte en la Universidad Alberto Hurtado de Santiago, Chile y como curador independiente de arte contemporáneo.
} 


\section{El lugar y el cuerpo de la tortura: casos de América Latina}

Dentro de las representaciones de los lugares de la tortura en las dictaduras latinoamericanas, una de las propuestas visuales más interesantes se desarrolló en la ciudad de Rosario en el año 1968. En ese año, el Grupo de Arte de Vanguardia de Rosario desarrolló diversas acciones mancomunadas para denunciar la represión que vivía el país. Por aquellos años, la dictadura del general golpista Carlos Onganía pretendió alejar el fantasma del peronismo a través de una serie de medidas que apuntaron a debilitar el poder de sindicatos, congelar los sueldos, reprimir a los estudiantes y censurar espacios culturales. Al ver el estrangulamiento social, los artistas del Grupo de Artistas de Vanguardia, con financiamiento del Instituto Di Tella, propusieron un Ciclo de arte experimental que ofreció algunas de las obras más radicales del arte argentino en los años 60.

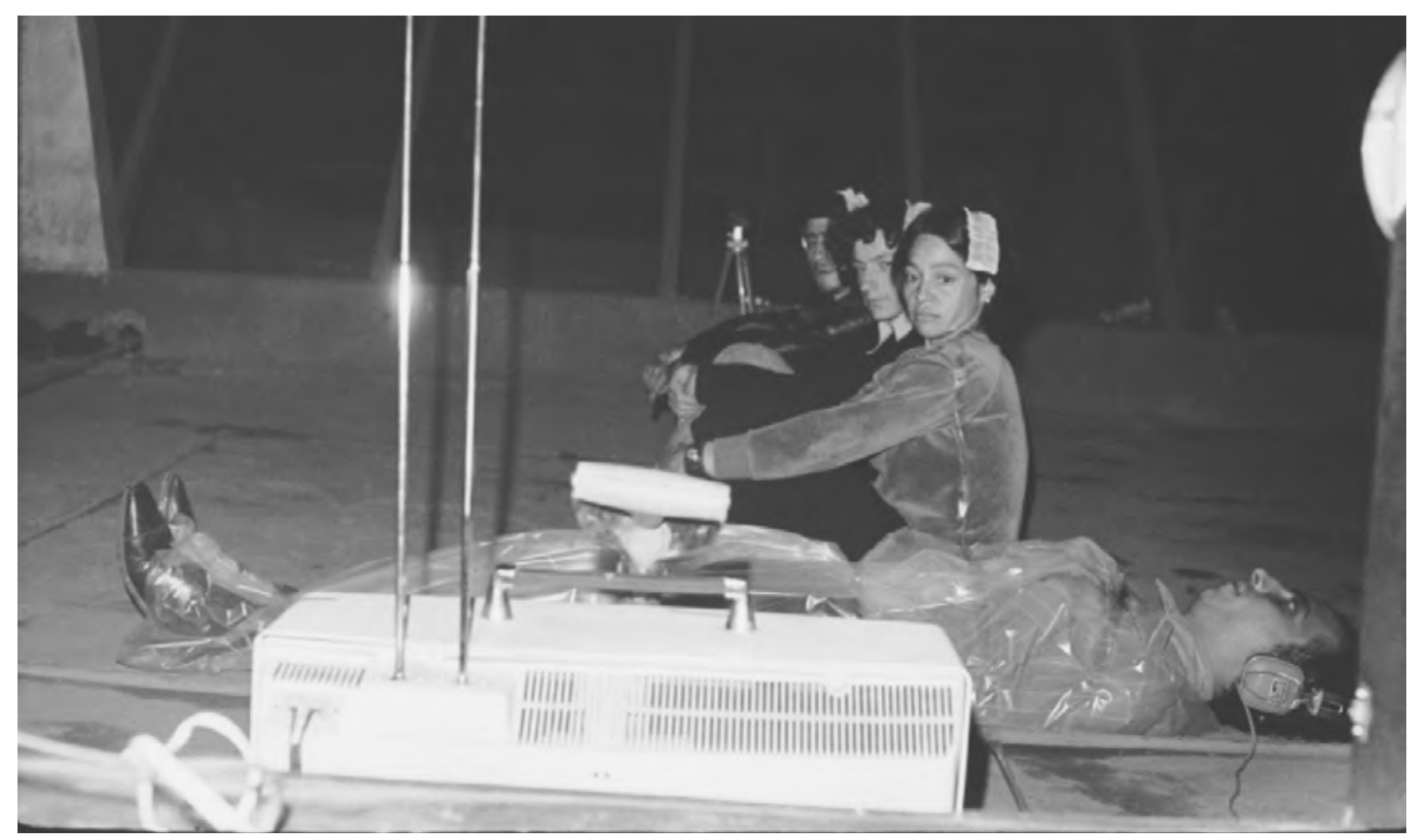

Signometraje: Tentativa Artaud, 1974.

(Foto: cortesía Ronald Kay) 
Como ejemplo de lo anterior y en el marco de dicho evento, la artista Graciela Carnevale presentó una controversial acción conocida como Encierro y escape. La obra en un inicio consistió en invitar a través de anuncios en prensa escrita a la inauguración, lugar donde Carnevale literalmente encerró a los asistentes. Con una temeraria acción Carnevale le puso candado a la mampara del local y en virtud de que nadie acudía a abrirlo, los espectadores -ahora prisioneros- comenzaron a desesperarse, generándose una tensión con quienes los observaban desde afuera. Según cuentan Ana Longoni y Mariano Mestman en su libro Del Di Tella a "Tucumán Arde": Vanguardia artística y política en el '68 argentino, una súbita patada desde el exterior quebró la mampara permitiendo la fuga.

Ahora bien, consignemos que la obra no pretendía en ningún caso un riesgo para los asistentes, más bien su trasfondo apeló a generar una experiencia de prisión fuera de la prisión. Los sujetos eran observados desde afuera como un experimento de arte. El filósofo Michel Foucault señala, en Vigilar y Castigar, que la prisión contiene una doble condición de adentro y afuera, siendo el lugar donde los individuos castigados siempre son observados. La obra motivó la reacción de escape también desde afuera consumando de esta forma la pieza de Carnevale.

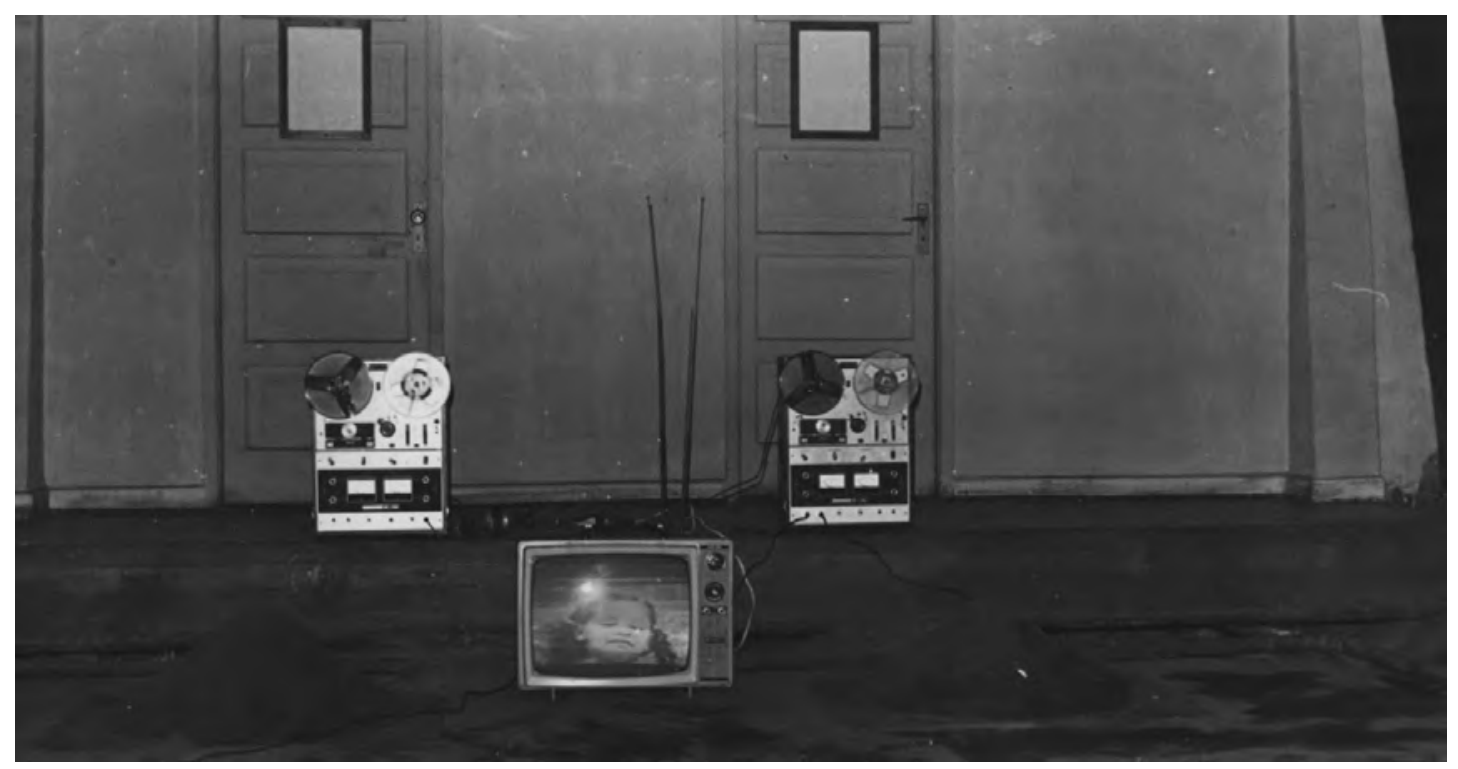

Signometraje: Tentativa Artaud, 1974.

(Foto: cortesía Ronald Kay) 
Algunos años después del '68 argentino, Chile experimentó uno de los momentos más oscuros de su historia reciente. Miles de chilenos sufrieron el encierro y la tortura en campos de concentración durante la dictadura de Pinochet. Mientras los medios locales omitían esta información, la prensa internacional daba cuenta del trágico destino de personas e incluso familias completas al interior de los recintos de detención. Un año después del golpe de Estado, un grupo de investigadores y artistas visuales realizaron una experiencia performática que proponía asimilar el dolor del encierro y la tortura. La pieza se llamó Signometraje: Tentativa Artaud y fue realizada en el Departamento de Estudios Humanísticos (DEH) de la Universidad de Chile por la artista Catalina Parra, el filósofo Ronald Kay y el poeta Raúl Zurita, entre otros participantes. En el inhóspito ático del DEH los miembros de esta experiencia procedieron a realizar una acción basada en técnicas vocales y corporales tomadas de la obra de Antonin Artaud El teatro y su doble con la idea de asimilar el dolor por medio de la expulsión del lenguaje formal. A principio de los años 70 en Alemania, Ronald Kay y Catalina Parra habían entablado una relación de trabajo y amistad con el videísta Wolf Vostell. Kay y Parra conocían en detalle el trabajo de Vostell, el cual integraba múltiples elementos visuales, desde televisores hasta bloques de concreto (como resultado de esta relación de trabajo, la instalación El Huevo fue presentada en Chile durante los meses de septiembre y octubre de 1977 en Galería Época). En función de esto, en el ático dispusieron elementos básicos como cuerdas, plásticos y tierra, los que se combinaron con un televisor, grabadoras, cintas magnetofónicas y un micrófono. La experiencia procedió en una catarsis individual y colectiva que emuló la sensación de encierro y tortura. Para ello los participantes se envolvieron entre plásticos y cuerdas y repitieron interminablemente el poema Ratara de Artaud, que no es más que la reiteración de palabras y sonidos totalmente inentendibles. La idea principal era expulsar la lógica del lenguaje para con ello desplazar el acto teatral alcanzando un trance físico y emocional que asimilase el dolor físico y psicológico. En palabras del propio Kay, exponerse a "la alta tensión" de lo que se vivía por aquellos días.

Por instantes aquel ático evocó un centro de tortura. Dos años después y por esas ironías del destino, el DEH fue tomado por los militares transformándose en un cuartel de la DINA (Dirección Nacional de Inteligencia), organismo encargado de la desaparición de militantes y simpatizantes del partido comunista. La performance en este caso vaticinó el oscuro destino del lugar. Actualmente el edificio alberga las dependencias del Museo de la Solidaridad 
Salvador Allende. Esta pieza permaneció en el silencio de la historiografía chilena por más de 30 años, hasta que el año 2008 Ronald Kay expone los archivos de la experiencia en la muestra "Tentativa Artaud" en el Museo Nacional de Bellas Artes.

Otro interesante caso de representación del lugar de tortura acontece en el año 1977. El grupo mexicano Proceso Pentágono (compuesto por los artistas Felipe Ehrenberg, Carlos Finck, José Antonio Hernández y Víctor Muñoz) realizó una provocadora pieza llamada La cámara de tortura. Tomando como antecedente los atropellos a los derechos humanos ocurridos en Tlatelolco en 1968 y los asesinatos de estudiantes a manos del grupo Los Halcones en 1971, Proceso Pentágono desarrolló diversas estrategias de corte conceptual para explorar la denuncia política y la crítica a la institucionalidad cultural. La cámara de tortura fue realizada para la X Bienal de Jóvenes de París que tuvo lugar en el Palais de Tokyo. El grupo recibió una invitación de parte del curador uruguayo Ángel Kalenberg (quien por esos años simpatizaba con la dictadura cívico militar de Uruguay) para participar como invitados al célebre evento parisino. Las simpatías políticas de Kalenberg no fueron vistas con buenos ojos por los miembros de Pentágono. Debido en parte a esta relación es que los jóvenes mexicanos presentan una sala pentagonal (con la connotación irónica al edificio de la oficina de inteligencia de Estados Unidos) que simuló ser una sala de tortura policial.

La sala disponía de una silla de interrogación, lámparas para iluminar a los interrogados, además de una serie de elementos eléctricos que emulaban objetos de tortura. En los muros los artistas dispusieron periódicos con la información acerca de las protestas que se realizan en México y en las distintas dictaduras de Latinoamérica. En los muros exteriores se podían apreciar siluetas de personas anónimas que observaban el interior de la sala como una forma de alegorizar el silencio cómplice de los medios de comunicación. La obra era un llamado de atención sobre la represión policial, entendiendo con ello que cuando los militares asumen y ejercen el poder, la policía suele ser un silencioso cómplice.

Podemos leer que la oficina policial de Proceso Pentágono, en el marco de un evento internacional de institucionalidad cultural como la Bienal de París, proponía evidenciar en el marco de la cúpula cultural parisina el revés de lo difundido por los medios oficiales. El grupo de Ehrenberg dejó al descubierto los mecanismos de opresión que se daban en México y en todo el continente. El lugar de la tortura fue más allá del local, el ático o el cuartel, se presentó como la validación institucional otorgada a partir del silencio cómplice de muchos poderes fácticos que se vieron beneficiados por aquellas dictaduras y regímenes autoritarios. 
El uso del cuerpo ha sido una constante para los artistas que han denunciado actos de violación a los derechos humanos, ya sea a través su propio cuerpo como soporte o usando la imagen del cuerpo de otro. En esta última línea encontramos el trabajo de los artistas chilenos Hernán Parada, Elías Adasme y Luz Donoso, quienes a principios de los años ochenta realizaron una serie de acciones callejeras a modo de protesta. Por medio de la difusión de fotografías y fotocopias con el rostro de personas anónimas daban cuenta de los crímenes acontecidos durante la dictadura de Augusto Pinochet. En la llamada Acción de apoyo: Intervención de un sistema comercial, el grupo intervino la vitrina de una tienda de electrodomésticos. En los televisores dispuestos para la venta apareció durante horas el rostro de una mujer sin identificar. La temeraria acción funcionó como un mecanismo de infiltración, desplazando el espacio de la galería de arte al lugar del diario tránsito peatonal. El rostro televisivo de las figuras ochenteras era reemplazado por una cara anónima, la cual en silencio clamaba por justicia en un gran escaparate. Así, mirando a la calle, escenario donde comúnmente se reprimían las protestas ciudadanas, varios televisores exponían una cara que el régimen quería ocultar ${ }^{2}$.

En Brasil el tono de este tipo de denuncia fue de alto impacto. Tal es el caso del artista brasileño Artur Barrio, quien en 1970 presentó en la ciudad de Belo Horizonte la polémica pieza Trouxas Ensanguentadas: Situação / Bultos Ensangretados: Situación. La acción pretendía rechazar la política de extrema represión a manos de la dictadura de Emilio Garrastazu Médici. Para ello Barrio dispuso de cuarenta y cuatros libras de carne y huesos de animales, que fueron envueltos en una tela blanca y arrojados a la calle.

Cabe recordar que la dictadura del general Médici ha sido considerada como una de las más represivas en la historia latinoamericana. Debido al temor de levantamientos guerrilleros, Médici utilizó brutales métodos de disuasión y tortura para atemorizar a la población. Los Esquadraos da Morte eran una organización ligada a los organismos de inteligencia que tenían la misión de erradicar a supuestas bandas delictuales de los barrios pobres y favelas, sin embargo sus objetivos muchas veces apuntaron a miembros la guerrilla urbana de oposición. Debido a esto, no era extraño que se encontraran este tipo de bultos en las calles, en sitios eriazos o en los ríos. Los bultos hechos por Barrio dejaron atónitos al menos a 5.000 personas en el Parque Municipal de Belo Horizonte y, como era de esperarse, la policía se hizo presente en el lugar, retirando los objetos y llevándolos donde peritos para su identificación. 
Como parte de la misma exposición "Desde el cuerpo a la tierra", el también artista brasileño Cildo Meireles realizó en el mismo parque otra obra radical. La pieza se llamó Tiradentes: Totem-Monumento ao Preso Político /Tiradiente: Totem-Monumento al preso político y consistió en instalar en el centro del parque un poste de ocho pies de alto en el cual Meireles amarró diez gallinas vivas, las que fueron rociadas con combustible y luego encendidas. La obra tuvo como trasfondo la fecha de la celebración del héroe nacional de la independencia de Brasil conocido popularmente como el Tiradentes.

En tiempos de la independencia Tiradentes había sido condenado a muerte por la corona portuguesa por apoyar la causa independentista. Su ajusticiamiento público fue un acto macabro. Su cabeza fue clavada en un poste en el centro de la ciudad de Río de Janeiro y su cuerpo fue mutilado y exhibido en distintos lugares como medida disuasiva. Se cuenta también que su acta de ajusticiamiento fue firmada con su propia sangre.

La imagen del Tiradentes había sido utilizada por las dictaduras para sublimar al pueblo a su beneficio. Debido a ello, Meireles toma la histórica figura y la re-significa provocando el efecto inverso. Basado en la tradición de los ritos Yorubas (fuertemente arraigados en la cultura afro-latina) Meireles sacrifica las gallinas para declarar su rechazo a la violencia militar. Las gallinas reemplazaron el cuerpo de Tiradentes y se contextualizaron con las muertes de los presos políticos de la dictadura. La imagen del mártir vuelve al pueblo resignificada bajo un rito religioso-popular ${ }^{3}$.

Otra de las piezas que también simbolizó de manera urbana la desaparición de los cuerpos en contextos de dictadura fue realizada en Argentina por los artistas Rodolfo Aguerreberry, Julio Flores y Guillermo Kexel en 1983. La acción de arte efímero se llamó El Siluetazo y tuvo como escenario las calles de Buenos Aires ${ }^{4}$.

Durante ese año el número de desaparecidos en Argentina sumaba cifras alarmantes. El "Proceso de Reorganización Nacional" Ilevado a cabo por los militares generó duros escenarios represivos. Además, como bien es sabido, los militares se embarcaron en la recuperación de las Islas Malvinas bajo el supuesto de recobrar la unidad nacional. El fracaso bélico y las lamentables bajas de jóvenes militares argentinos provocaron un fuerte descontento ciudadano que terminó por desbancar a la dictadura. 
En este escenario, los gestores del El Siluetazo buscaron el apoyo de otras organizaciones sociales como las Madres de Plaza de Mayo. La acción se pensó como un acto de participación colectiva y propuso la creación de cientos de siluetas de detenidos desaparecidos estampados en los muros de las calles. El concepto proponía el cuerpo anónimo como símbolo de la ausencia y la injusticia. Sin un rostro el contorno fue uno y todos a la vez. Se realizaron previamente talleres de stencil y pintura mural al aire libre, incluso algunos artistas utilizaron su propio cuerpo como modelo para estampar las siluetas. Todo era válido para que cientos de personas salieran a las calles a imprimir cuerpos. De forma espontánea muchos comenzaron a escribir los nombres de sus familiares desaparecidos.

De esta forma, la ciudadanía y el arte se tomaron el espacio público para exponer el dolor de los cuerpos ausentes, estableciéndose con ello una sinergia colectiva de un cuerpo social activo. Posteriormente se realizaron otros siluetazos, sin embargo, podemos leer el primero como un anticipo de las elecciones democráticas que se realizaron en el mes siguiente, cuando Raúl Alfonsín asumió la presidencia.

Las obras que reflexionan sobre el espacio y el cuerpo de la tortura tuvieron como propósito denunciar y socavar la aparente imagen de normalidad y progreso de las dictaduras, poniendo de relieve (tanto en espacios privados como públicos) la violencia ejercida y el atropello a los derechos humanos. No hay duda de que la violencia ejercida sobre los espacios y los cuerpos condicionó un estado de alerta y activó mecanismos de denuncia por medio del camuflaje y del impacto mediático. Escaramuzas artísticas que, en mayor o menor medida, contribuyeron al advenimiento de las democracias en el continente.

\section{Corriendo riesgos: arte, calle y coyuntura política en el Chile reciente}

Hace un par de semanas el Museo de Arte Contemporáneo inauguró la exposición Memoria y experimentalidad: Chile años 70 y 80 . Una muestra que recoge, en su mayoría, el trabajo de artistas que durante la dictadura realizaron piezas pictóricas, de corte conceptual y performático. Muchas de estas obras apuntaban a denunciar, por medio de estrategias de subversión simbólica y de camuflaje, los abusos que desarrollaron los oscuros organismos de seguridad en Chile. Hoy, aquellas piezas representan gran parte del mosaico iconográfico-cultural del país en dicho período. Nos referimos al trabajo de Lotty Rosenfeld, Carlos Altamirano, Elías Adasme, Alfredo Jaar, Cecilia Vicuña, Víctor Hugo Codocedo, Hernán Parada, Valentina Cruz, Las Yeguas de la Apocalipsis, entre otros. 


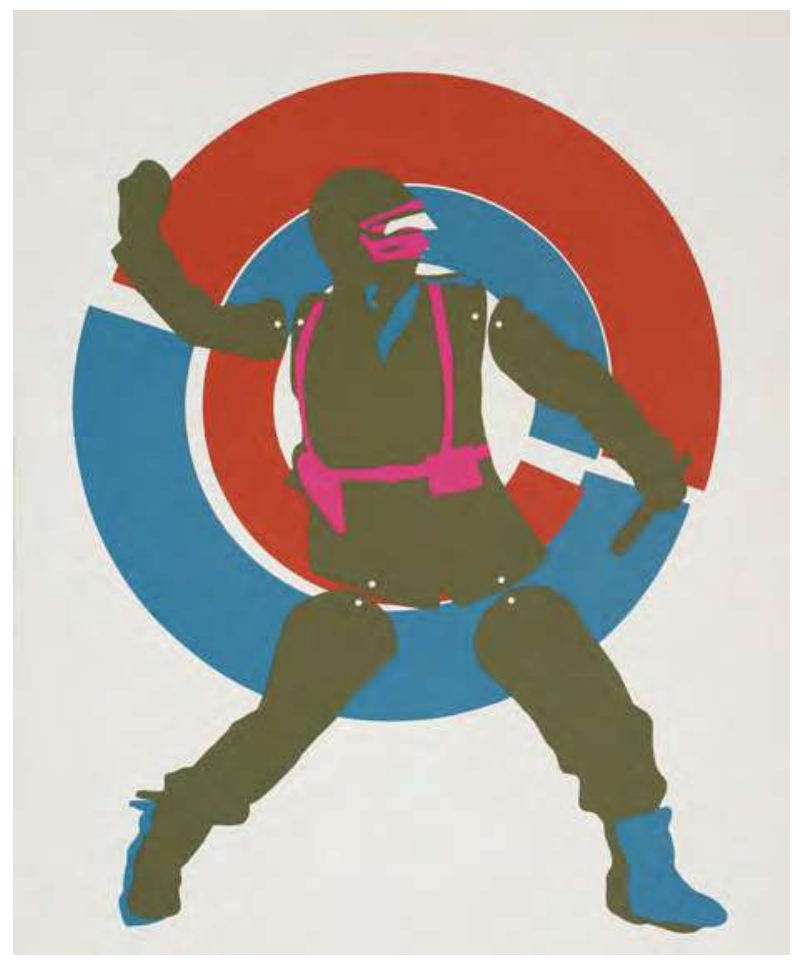

Guillermo Nuñez, Serigrafía Tren de la Cultura, 1970. (Foto: cortesía MAC)

Estos reconocidos nombres ${ }^{5}$-sólo por mencionar algunos de la exposición- a medida que el malestar ciudadano se expresaba por medio de protestas callejeras y también por medio de escaramuzas armadas, se tomaban las calles con arrojadas acciones que además de intervenir el espacio público, se concibieron como obras de registro fotomecánicos.

Pese a que muchas de estas acciones resultaron inentendibles o ambiguas para las autoridades de la época, los artistas no se dejaron amilanar por la militarización y las posibles consecuencias que su actuar en la calle pudiera generar. Sin duda, este período marcó un momento único en el país y en nuestra historia del arte local, en el cual los artistas alinearon sus proyectos a la efervescencia político-social imperante. Había un enemigo y el arte y los artistas no podían estar indiferentes. 
Hoy, algunos críticos - como Guillermo Machuca en su reciente libro - han rebatido la condición en extremo subversiva de algunas de estas piezas, argumentando que fueron concebidas bajo las mismas reglas de difusión del arte oficial sin sufrir un mayor tipo de censura o blanqueo. Fuese ese o no el caso, lo que sí tenemos claro es que hubo una preocupación efectiva por parte de los artistas por los conflictos reales y presentes como la opresión y la tortura. Los registros dan cuenta de ello, más allá de las actuales interpretaciones.

Una vez recuperada la democracia, el foco de atención respecto a la utilización de la calle como elemento estético definitivamente cambió. El retorno a la universidad de muchos de estos artistas y teóricos conllevó también la oficialización de aquel discurso "subalterno" - mejor conocido como Escena de Avanzada - a partir de su validación académica. Surgen nuevos museos, galerías y centros culturales, muchos de ellos se vuelven espacios oficiales y otros comerciales, en los cuales la calle hace ingreso como registro y creación.

El acto performático nacido desde las artes visuales, debió ingresar al museo o a la galería como ejercicio de validación y circulación. La condición efímera, rebelde y/o mutable de la calle y su acción performativa se adoctrinó al espacio de circulación "oficial" o de "validación" el que ha dependido fuertemente de una robusta tradición academicista de arte $^{6}$, como ha sido característico en nuestro país.

Otro recurrente fenómeno de "oficialización del acto callejero" fueron los carnavales culturales. Estos eventos se transformaron en uno de los símbolos de la política cultural de la Concertación. Música y baile coronaron fiestas ciudadanas, algunas de ellas transmitidas por televisión. Sumémosle a esto, los celebrados espectáculos masivos de Santiago a Mil con las compañías La Furia del Baus o Royal De Luxe (recordemos a la muñeca gigante y al tío escafandra que tanto irritaron a Justo Pastor Mellado). Es en esta misma calle, donde también numerosos artistas desconocidos imprimen día a día, por medio de grafitis y esténcils, los muros y veredas de la ciudad?

Ello contrasta, por ejemplo, con los colosales espectáculos de luces que se hicieron sobre el frontis de La Moneda para conmemorar el bicentenario. Muros ambos. Uno anónimo, invisible ante los medios y cargado de contingencia, mientras que el otro, institucional, híper-mediatizado y cargado de una lectura republicana y patriotera. 

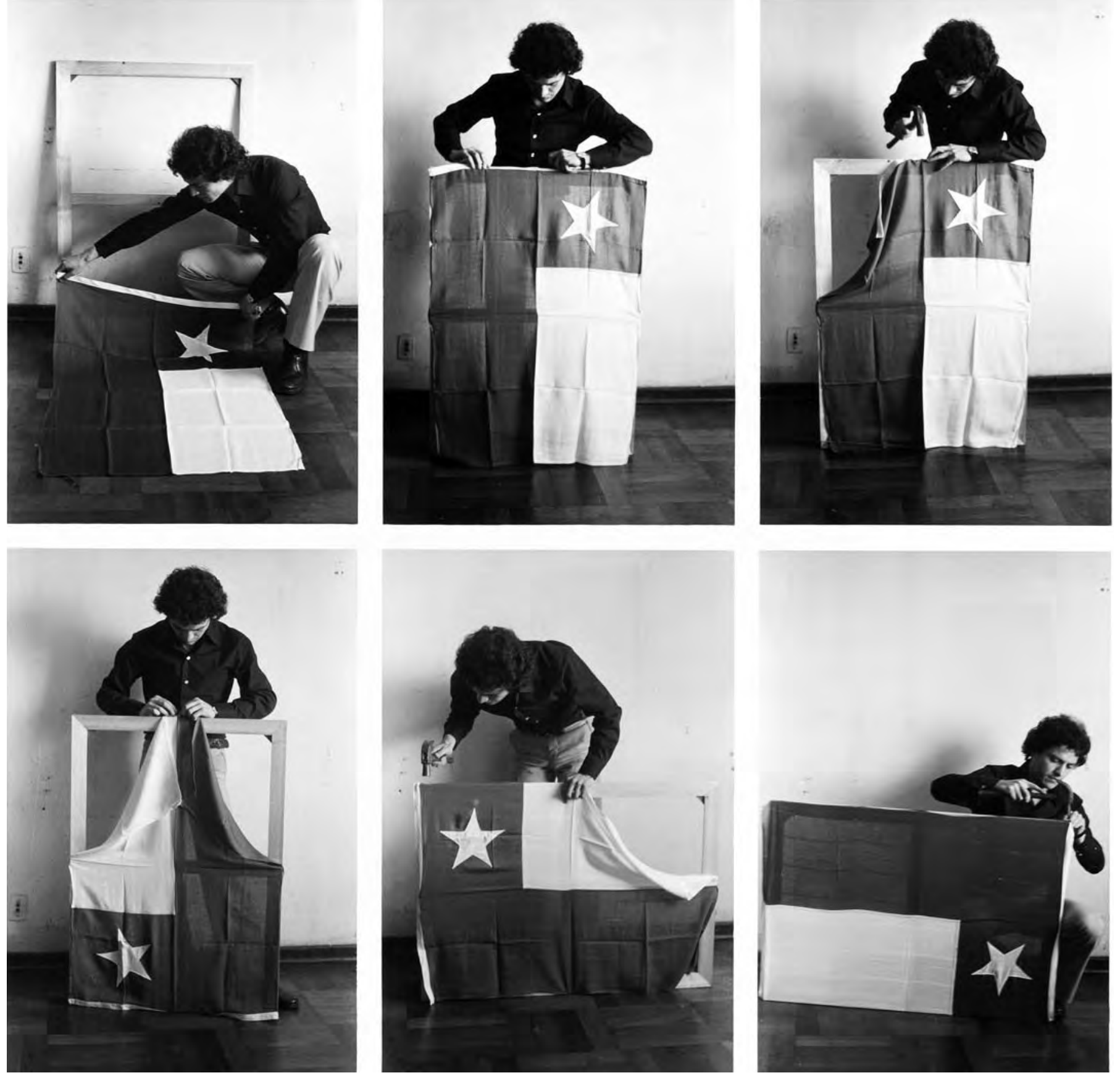

Víctor Hugo Codocedo, Intervención a la bandera (Serie "La Bandera"), 1979. (Foto: cortesía MAC) 
Las multitudinarias protestas en contra del proyecto HidroAysén y luego el apoyo al movimiento estudiantil han sembrado la agenda noticiosa de los últimos meses en el segundo año de gobierno del presidente Sebastián Piñera. Ciudadanos que han desfilado por las calles con desencanto y malestar. A las clásicas reivindicaciones por el derecho a la educación, la salud y el trabajo se le suma hoy el derecho a las libertades sexuales y al respeto por el medio ambiente. Una diversidad cultural que no se condiciona a un grupo etario o político determinado. Sino, más bien, a simples ciudadanos que claman por aquello que creen les fue injustamente usurpado. Cientos o miles de personas se han tomado simbólicamente las calles de todo Chile con ingeniosas marchas y cánticos.

Estos jóvenes, como hemos visto, utilizan las redes sociales como Facebook o Twitter para coordinarse y llamar la atención de los medios. Canciones y videos, cargados de sarcasmo, son subidos diariamente a Youtube para promover masivamente sus demandas. Una generación que durante las protestas en las calles y en las tomas de colegios y universidades realizan Twitcams en vivo para informar a la ciudadanía. Transmisiones que muchas veces han servido como herramienta para desacreditar la información que entregan los medios oficiales.

Todas estas manifestaciones callejeras, al igual que las realizadas en dictadura, han ido acompañadas de acciones performáticas. Éstas surgen espontáneamente como potentes gestos de rebeldía frente a la autoridad. Desde estudiantes ironizando "la playa de Lavín" (por las vacaciones anticipadas que el entonces ministro de educación decretó) hasta las masivas coreografías flashmobs en la que cientos de participantes personifican con vistosos disfraces a íconos de la cultura pop como Thriller o The Wall.

Ahora bien, de las acciones performáticas sobre el malestar social, hay una que me ha llamado profundamente la atención, una en que unos jóvenes han decidido correr 1.800 horas, durante 24 horas, mediante un sistema de postas, durante 75 días alrededor de La Moneda en demanda de cambios al actual sistema educativo ${ }^{8}$. Una corrida permanente, en pleno invierno, que comenzó el 13 de junio y terminará el 27 de agosto 9.

La idea surgió de un grupo de estudiantes de la Escuela de Teatro de la Universidad de Chile como un acto de desagravio frente a la compleja situación que atraviesa la educación en el país. Un evento coordinado en el cual cualquier ciudadano se inscribe y participa corriendo, lo que pueda, alzando una bandera negra. Hay un checkpoint frente al diario La Nación, puntos 
de hidratación, estudiantes de kinesiología para atender emergencias, un equipo que actualiza el marcador de horas, una página web, un grupo en Facebook y ya van más de 4.000 corredores (estudiantes, oficinistas, deportistas, transeúntes) que han cumplido con más de la mitad del tiempo propuesto día y noche sin parar bajo una sola consigna: "Educación gratuita ahora". Una performance colectiva alrededor del máximo símbolo del poder político.

En cuanto vi a estos jóvenes correr, no pude sino recordar una performance realizada por Carlos Altamirano en 1981 llamada Panorama de Santiago. El título aludía a la obra del mismo nombre realizada a finales del siglo XIX y principios del XX por el pintor chileno Juan Francisco González (1853-1933). En aquella performance Altamirano portando una pesada cámara de video (aquellas con maletín) corre sin detenerse por las calles de Santiago desde el Museo Nacional de Bellas Artes hasta el frontis de la Biblioteca Nacional, mientras va recitando una y otra vez, infatigablemente, la frase: "Altamirano, artista chileno". La obra además de citar al paisaje presentado por la pintura de González, se podía entender también como una metáfora a la persecución realizada por los organismos de seguridad.

El video registro se presentó en un encuentro Franco-Chileno de video a principio de los 80 y fue expuesto por Altamirano en su muestra "Obra Completa" en el Museo Nacional de Bellas Artes en el 2007. En esta exposición, Altamirano situó, junto al cuadro de González, una mirilla en la cual el espectador podía ver la extenuante performance, mientras que al alejarse podía contemplar el cuadro ya mencionado.

Ahora bien, mi inmediata relación sobre el correr como gesto disruptivo de un malestar político parece funcionar en un estado simbólico. Sin embargo, ambas acciones poseen diferencias medulares en lo formal. El primero fue realizado en dictadura y representa una acción riesgosa, individual y de circulación expositiva restringida. Mientras que los jóvenes que correrán 1.800 horas la realizan en democracia y representan un acto permitido por la ley, colectivo, participativo y de difusión amplia.

Además, hay otra diferencia que me parece esencial y donde Altamirano respondió a algo clave. Su acción fue híper consciente sobre la condición y producción de arte. No en vano repitió durante su recorrido incansablemente la frase: "Altamirano, artista chileno." A mi entender, esto representó un acto de aguda crítica a la institucionalidad cultural representada por el inicio y el final: la Biblioteca Nacional y el Museo Nacional de Bellas Artes; esto en cuanto a la libertad de expresión y la persecución política que se vivía por aquellos años. 
Por su parte la que se realiza actualmente alrededor de La Moneda, no. En su consigna no hay un acto concientizado del actuar performático entendido como gesto de arte, sino más bien como acto social. También creo que esta diferencia no deslegitima una a favor de otra, sino que establece un punto de inflexión frente a cómo se enfrenta, desde el cuerpo como soporte visual, un gesto disruptivo en momentos históricos distintos, que apuntaban a objetivos diferentes.

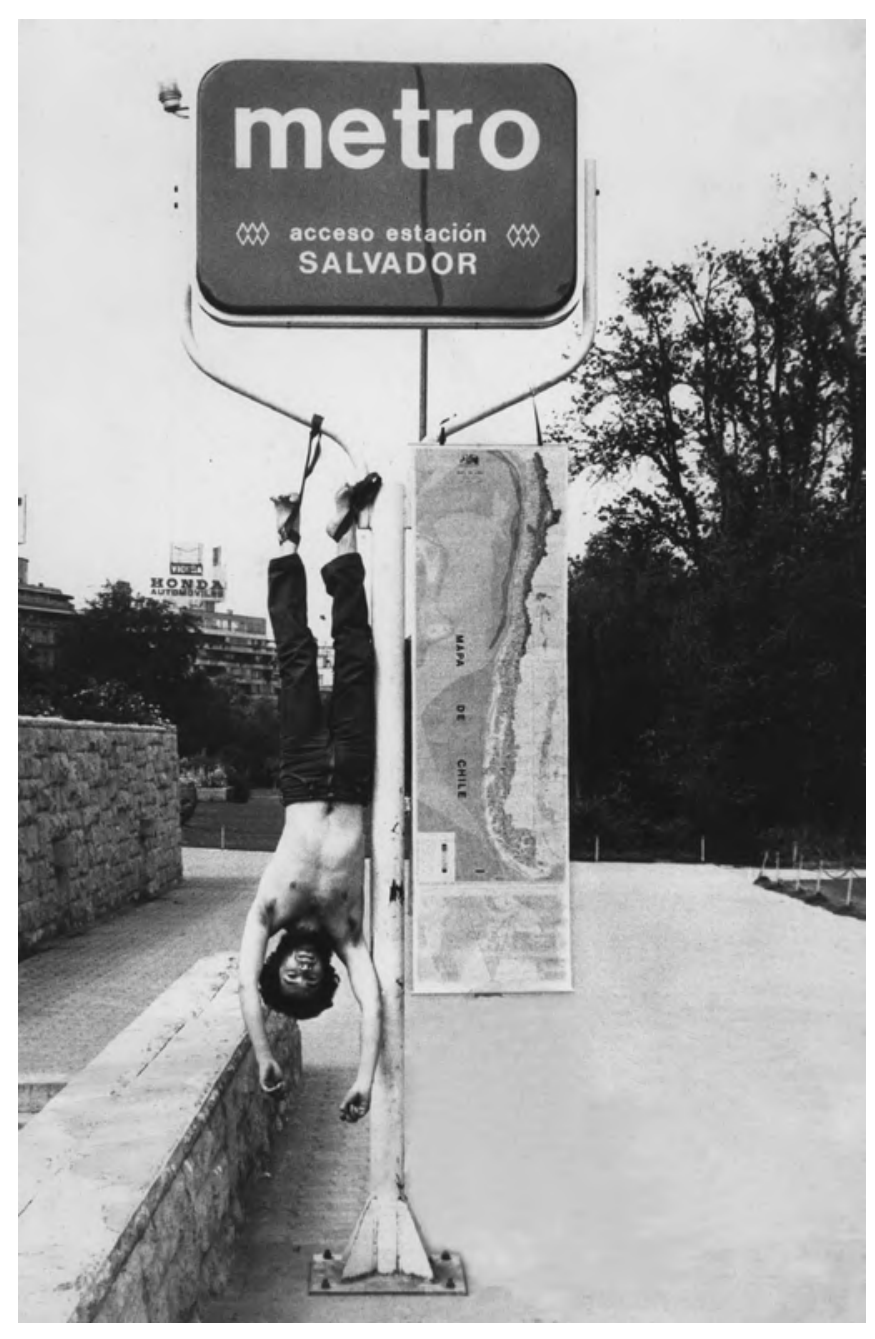

Elías Adasme, A Chile, 1979-1980. (Foto: cortesía MAC) 
Tomemos ahora un caso de las emblemáticas acciones que se presentan hoy en el MAC. Elías Adasme durante 1979 y 1980 desarrolló la obra A Chile. Una serie de intervenciones urbanas y en las cuales una de las más arrojadas consistió en colgarse del aviso de acceso al metro Salvador con su torso desnudo al lado de un mapa de Chile. El acto de Adasme representa no sólo el gesto disruptivo que denota los mecanismos de tortura, sino que también reflejó un estado de conciencia de los mecanismos de producción de arte operando simultáneamente con la contingencia callejera, apropiando y subvirtiendo la calle y sus códigos.

Pero volvamos a las últimas semanas. Acaso ¿no resulta curioso que habiendo tantos conflictos hoy en el país, los artistas y las instituciones no se manifiesten con obras (performáticas o de otra índole) frente a ello? Es cierto que muchos estudiantes de arte han colaborado anónimamente en las gestiones estudiantiles, en tomas y en marchas aportando creatividad y energía ${ }^{10}$. Sin embargo, parece ser que los artistas profesionales y los espacios institucionales se resisten a trabajar con la contingencia del malestar social actual. ¿Por qué esta distancia? Quizás el modo de afrontar el arte está excesivamente teorizado y sujeto a las formalidades entregadas por la academia, que el sistema de arte requiere inevitablemente de un tiempo extenso de proceso para desarrollar "estrategias" que aborden formalmente la coyuntura".

Dentro de esta misma línea, es sabido que la utilización de temáticas que aborden la coyuntura son vistas como un aprovechamiento mediático, lo que rápidamente clausura una posible interpelación visual por parte del artista en el acontecer. Desconozco el motivo por el cual los artistas no parecen querer participar desde el arte en la coyuntura, como aconteció en dictadura, sino más bien anónimamente desde la sociedad civil.

Aunque los actos -aún cuando algunos sean generados por estudiantes de teatro que se ligan directamente con la performance- se establecen como acciones ciudadanas. No son pensadas bajo las lógicas del circuito del arte. No son pensadas para ser exhibidas en una galería o un museo, por el contrario, su registro se masifica por las redes sociales y por medios de comunicación alternativos. Son actos que no son realizados desde la esfera del arte, sino por estudiantes y ciudadanos molestos que apelan a la participación de la ciudadanía.

Los cacerolazos o las velatones que se realizaron valiente y anónimamente en muchas poblaciones en dictadura, hoy surgen con renovados aires gracias a la difusión que otorgan las redes sociales. Aquellas poblaciones intervenidas, también, en su momento por artistas que reaccionaban con obras a ese malestar. 
Los jóvenes que corren alrededor de La Moneda, ya llevan más de 1200 horas. Están cerca de finalizar su propósito. Realizando un acto inédito de protesta ciudadana, no pretenden detenerse a descansar. No es el momento de hacerlo. Son conscientes de que hoy se pueden realizar cambios, justamente, desde la calle. Mientras en las academias e instituciones seguimos discutiendo sobre el rol y los límites del arte a partir de la revisión de aquellas emblemáticas obras en dictadura, estos muchachos seguirán corriendo y corriendo motivados por cambiar el presente y el futuro del país.

\section{Notas}

1 Este escrito ha sido preparado especialmente para el presente número del dossier de la revista Poiésis. Con leves modificaciones del equipo del dossier de Poiésis, resume tres artículos publicados en la revista chilena Arte y Crítica. El Capítulo I corresponde a los artículos de los números 4 (enero-2013) y 5 (mayo-2013) y el Capítulo III corresponde al artículo del número 1 (julio-2012). Pueden consultarse en línea: www.arteycritica.org

2 Cabe mencionar que valiosas piezas de Luz Donoso fueron recuperadas y exhibidas en la exposición "Una obra hecha por otro es una obra de la Luz Donoso", curada por Paulina Varas en el Centro de Arte Contemporáneo de la comuna de Las Condes en octubre del 2011.

3 Ver Carliman, Claudia Brazilian Art under Dictatorship: Antonio Manuel, Artur Barrio and Cildo Meireles, Duke University Press, 2012.

4 Ver Longoni, A y Bruzzone, G comp. El Siluetazo, Buenos Aires, Adriana Hidalgo Editora, 2008.

5 Pienso en este sentido también en los diversos colectivos y asociaciones de artistas que en poblaciones realizaron obras de denuncia política durante la dictadura. Muchos de los cuales aún se encuentran en el anonimato debido al descuido o simple desidia de los historiadores del arte.

6 Importantes también han sido las Bienales de performances organizadas por el colectivo Deformes a partir del 2002. Éstas han surgido como instancias de investigación y exploración del cuerpo como soporte. Sumado a esto el trabajo de algunos artistas, preferentemente egresados universitarios, que han continuado realizándolas esporádicamente. Debemos sumar a ello también, el trabajo realizado por el colectivo Perfopuerto entre otros. Lamentablemente, estas prácticas han tenido una sistemática cobertura de un periodismo promiscuo como lo calificó en algún momento Guillermo Machuca - que busca la atención inmediata del evento freak, acompañado de una pobre atención por parte de la crítica especializada y la teoría.

7 Si bien el riesgo de los grafiteros a perder su obra es constitutiva de su quehacer, un lamentable incidente aconteció recientemente. Los grafitis que cubrían los muros en la ribera del río Mapocho fueron literalmente borrados con pintura gris, a principios de este año, por una ordenanza de limpieza emitida por la Municipalidad de Santiago y por Bienes Nacionales. Curiosamente, a los pocos días, en aquel sitio se instaló el mega proyecto "Museo Artedeluz" de la artista Catalina Rojas, un proyecto Bicentenario financiado por el grupo Enersis. Al parecer el criterio que primó en dicha toma de decisión, no estuvo en el debate sobre el posible valor estético e incluso patrimonial de las piezas borradas en relación a la nueva intervención, sino por sobre la masividad y el espectáculo visual que las proyecciones lumínicas podían generar. En entrevistas la artista ha argumentando que los grafitis iban a ser borrados de todas 
formas por aquella ordenanza. Lo curioso en este caso, es que el proyecto se llama "Museo Artedeluz", es decir, una metáfora de la "musealización" de la calle. El muro debe ser controlado por la institución y su respectivo espectáculo. Mientras que el mismísimo Museo Nacional de Bellas Artes apela a todo lo contrario con su proyecto "Museo sin muros".

8 Las 1.800 horas tienen relación al estudio de Marcel Claude que señala que el costo que el país necesita para solucionar el problema inmediato de la educación en Chile es de 1.800 millones de dólares al año.

9 Paralelamente se han realizado actividades como una maratón que comenzó en Santiago y terminó en Valparaíso, una Natatón de 48 horas seguidas y 1.800 paraguas en el centro de Santiago.

10 Los estudiantes de arte de la Universidad de Chile se sumaron con la actividad 48 horas de arte por la educación en la casa central de la misma universidad. Si bien la actividad es una respuesta propositiva, no es el reflejo de lo que se puede ver en el circuito profesional de arte, ni la reflexión en los medios especializados. La actividad que debió realizarse el viernes 5 de Agosto, tuvo que ser suspendida por los incidentes acaecidos el día anterior. 48 horas de arte por la educación será próximamente reprogramada.

11 Como ejemplo tenemos el caso de nuestro exponente en la Bienal de Venecia: Fernando Prats. Quien presenta obras relacionadas con el 27F o la tragedia de Chaitén. 